\title{
The Vermont Climate Assessment: A Problem-Based Model to Bridge National Climate Research and Local Resilience
}

\author{
ELIZABETH PALCHAK ${ }^{1 *}$, JULIE NASH ${ }^{1}$, GILLIAN GALFORD ${ }^{1}$ \\ Volume 3, Spring 2015 \\ http://dx.doi.org/10.3998/mjs.12333712.0003.005 \\ 'University of Vermont, Gund Institute, 617 Main Street, Burlington, VT 05401 \\ *Corresponding Author: Elizabeth Palchak, epalchak@uvm.edu
}

\section{ABSTRACT}

Released in June of 2014, the Vermont Climate Assessment (Galford et al.) was the first assessment in the country that followed the format of the National Climate Assessment in capturing climate change risks at a state level, across multiple sectors. This was the product of a graduate-level course conducted in workshop format that featured a problem-based learning project to inform the development of local resilience strategies. This paper describes development of the key elements of the course and best practices for this learning model, including two examples of local resilience approaches inspired by the Vermont Climate Assessment (VCA). This class model can be replicated in states and municipalities to communicate opportunities and risks to catalyze local resilience building.

Introduction

Climate change impacts and mitigation needs are well documented at the global and national levels. Yet climate change adaptations are inherently local in nature, which causes a critical mismatch of scale. Recognizing this gap, researchers at the University of Vermont developed the Vermont Climate Assessment (VCA) to gain a deeper understanding of climate change impacts to forest and water ecosystems, agriculture, the energy sector, and tourism in Vermont. The project engaged various 
stakeholders throughout the state, catalyzing important discussions on the opportunities for local resilience building based on the report's findings.

VCA was created as a problem-based learning (PBL) class at the University of Vermont's Gund Institute for Ecological Economics. This course contained many hallmarks of the PBL format, including class activities driven by authentic problems, self-directed learning, involvement of community partners, and the production of a public output (Wiek et al. 2014; Blumenfeld et al. 1991; Krajcik et al. 1994). Positive student outcomes from PBL include improved content knowledge, increased engagement and motivation, problem-solving skills, collaboration, and communication skills (Cho and Brown 2013). Within academic sustainability programs, PBLs have great potential, but the format and time requirement represent an executional challenge (Wiek et al. 2014). Given these challenges, the existing literature on PBL lacks a depth of evidence-based resources and potential models for project-based learning classes in sustainability (Wiek et al. 2014). Our paper analyzes the VCA as a case study that can be used as a replicable model for other problem-based learning courses addressing problems of sustainability.

\section{Building a course to address a problem}

The following section identifies the critical elements of the VCA course design and its relationship to PBL.

- Class activities driven by an authentic current problem. Climate change impacts are well documented at the national levels, but there is a lack of information on local-level impacts. The VCA grew out of the need for local-level information and the objective of creating materials to foster local resilience in Vermont. This focus on an authentic problem attracted a diverse class of ten graduate students from disciplines such as ecology, social sciences, policy, and engineering. The semester-long course started shortly after the release of the Third National Climate Assessment (Melillo, Richmond, and Yohe 2014), with the publication acting as a framework that guided and structured the final report.

- Student self-directed learning. The class participants discussed which chapters from the National Climate Assessment would be most relevant for Vermont and most interesting for each researcher. Together, the instructor and students decided to eliminate chapters on transportation, land use, and sea 
level rise. Each student chose one or two focus areas and began developing associated chapters such as energy, water, agriculture, tourism, and forests, becoming class specialists in their subject area. Students conducted a needs-based assessment on their topic area to refine the focus and minimize duplication with existing publications or programs.

- Involvement of community partners. The class workshop format allowed external experts to play a role. Community partners like NOAA/National Weather Service meteorologists, Agency of Natural Resources officials, recreation businesses, and farmers provided content expertise through class presentations. Community partners also critiqued and evaluated student chapters.

- Creation of a public report. The final project included an extensive document with graphics. The class also hosted a press event at which panels of students and community partners spoke about the personal impacts of climate change and opportunities to build resilience in the state. The student authors presented their findings, gaining valuable experience in public speaking, stakeholder interaction, and communication with the media.

\section{Judging success}

Judging the success of the VCA requires a nuanced exploration of student outcomes, including the process and final product of the course. A useful framework for this critique examines the currency, context, and content of the course (Dobson and Thompkinson 2012).

- Currency. Climate change is a topical issue, particularly in Vermont. The devastating effects of Hurricane Irene in 2012 shifted the discourse on climate change to issues of mitigation, adaptation, and resilience building. Many residents are hungry for information on how to insulate their communities from another Hurricane Irene, or worse. The VCA offered information on this timely issue.

- Context. The framework of the course was appropriate and challenging for graduate students, involving as it did the creation of a major public report and a final press release. Developing individual chapters allowed young professionals and scholars to integrate professional interests, while interactions with stakeholders and the media created invaluable lessons in communication.

- Content. Climate change science and communication is rich ground for learn- 
ing. The complexity of the content, with its multiple focus areas, and the inclusion of outside stakeholders gave students opportunities to grapple with information across disciplinary boundaries.

Challenges of the PBL course design include a lack of structure and the difficulty of assessing the final synthesis of the material. Final exams are not typically part of the PBL design, leaving a gap in "measuring the impact of PBL" (Wiek et al. 2014). In the VCA, students were largely responsible for their own learning and relied heavily on self-study without a final assessment of student outcomes. Also, since they were the in-class subject "experts," it was impossible for students to know how extensive their knowledge was in their topic area. Addressing these weaknesses without changing the fundamental design of PBL is challenging. In this case, including outside stakeholders as reviewers helped to increase and bolster students' content knowledge.

\section{Bridging the gap: Local resilience strategies}

Since its release, interest in the VCA has spread throughout the state, catalyzing discussions and action on climate change resilience in Vermont. The instructor of the course was interviewed a dozen times by radio and newspaper outlets across Vermont and has presented at various venues, including the Vermont Legislative Summit on Climate Change. In addition, several graduate students have presented their work at regional conferences.

The release of the VCA also spurred innovative approaches to resilience building in Vermont. During the months following the release of the VCA, students at Middlebury College used the VCA to create a climate change adaptation plan for their campus. After studying the Vermont Climate Assessment as part of an academic course, students isolated Middlebury's areas of highest vulnerability to climate change. In a final report and presentation, they recommended strategies to "increase the College's resilience to climate change" to the Middlebury Board of Trustees (Baker et al. 2014). For example, they recommended investing in an electricity microgrid and considering the implications of tree species migration out of Vermont.

In another example of local resilience building, the community of South Burlington is currently competing in a nationwide competition to reduce overall energy use. Members of the Energy Committee in South Burlington are using information 


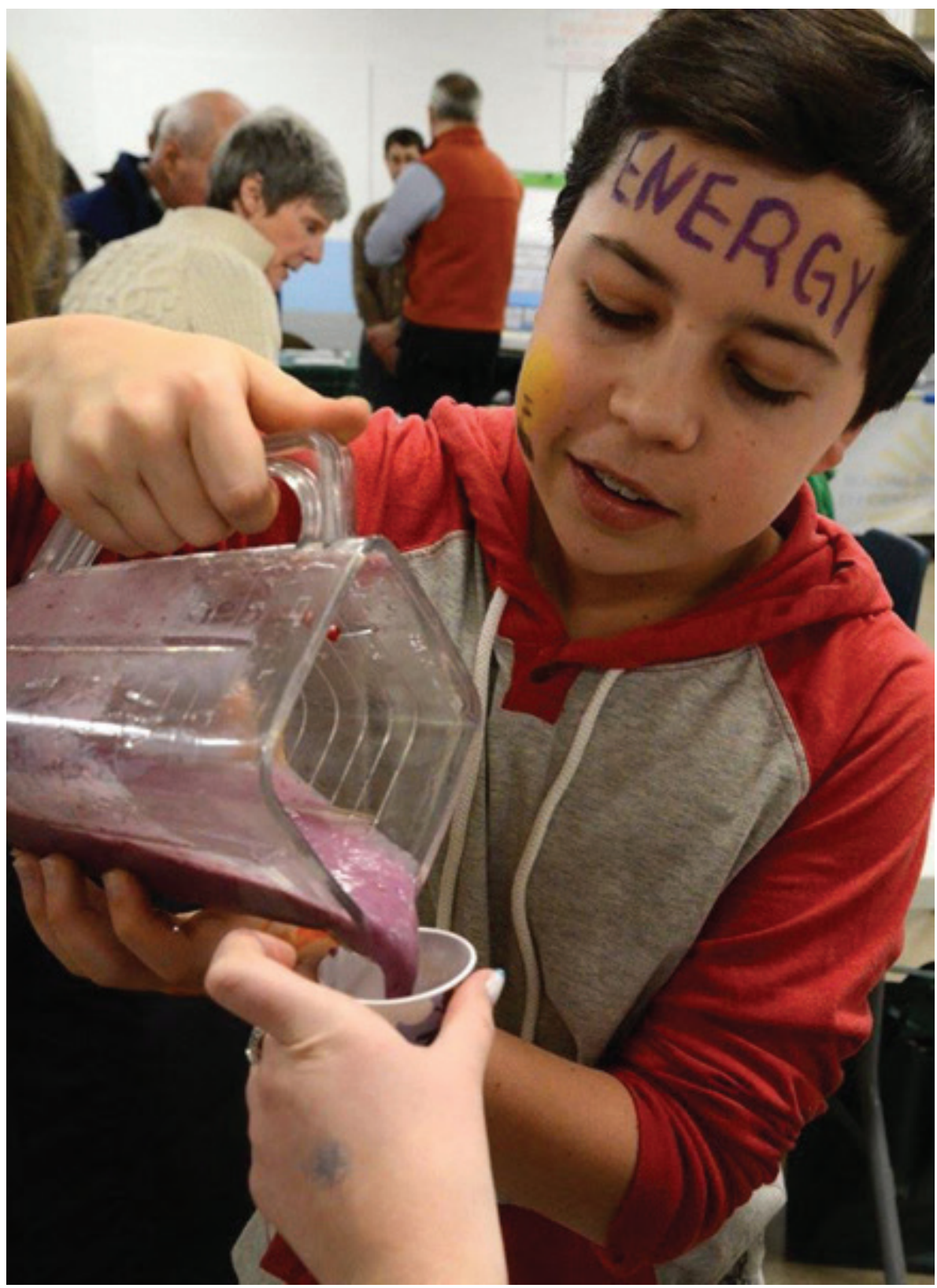

Figure 1. A young helper pours drinks blended by bicycle at the kick-off party for South Burlington's energy competition. South Burlington is integrating research from the VCA to increase energy efficiency in the community. (Photo by Lee Krohn) 
from the VCA on behavior change and residential energy use to make their documents more accessible and compelling. Behavior change is covered at length in the energy chapter of the VCA as a climate change mitigation strategy. After observing a presentation about the VCA, the South Burlington Energy Committee partnered with one of its authors to apply the research from the VCA to documents and various events related to reducing energy use in South Burlington.

Small business owners, community members, utility managers and farmers have all commented on the relevance and importance of the VCA. This state-level assessment gives Vermont citizens information on the effects of climate change at the local level, where it's most relevant and can have a big impact.

\section{Conclusion}

Problems of sustainability, sometimes referred to as "wicked" problems for their complexity, might best be addressed in the curriculum as PBL courses. Paradoxically, the design of effective PBL courses might itself be a "wicked" problem (Dobson and Thompkinson 2012). Many excellent PBL courses exist, but case studies emphasizing the design of these courses would allow them to be duplicated in other contexts and places. Sharing the structure of the VCA course, including its process and product, allows other scholar-teachers to reproduce the richness and value of the Vermont Climate Assessment. Higher education is uniquely positioned to grapple with the multitude of critical issues in sustainability, and this paper offers a tested framework.

\section{References}

Baker, I., A. Cort, D. Kluchiniski, and J. Parker. 2014. "Recommendations for Vulnerabilities of Middlebury College When Facing Climate Change 2014-2035.” Middlebury: The Middlebury School of the Environment. http://www.middlebury.edu/media/view/488126/original/ team_bobcat_report_for_2014.pdf.

Blumenfeld, P. C., E. Soloway, R. W. Marx, J. S. Krajcik, M. Guzdial, and A. Palincsar. 1991. "Motivating Project-Based Learning: Sustaining the Doing, Supporting the Learning." Educational Psychologist 26 (3-4): 369-398. doi:10.1080/00461520.1991.9653139.

Cho, Yonjoo, and Catherine Brown. 2013. "Project-Based Learning in Education: Integrating Business Needs and Student Learning." European Journal of Training and Development 37 (8): 744-765. doi:10.1108/EJTD-01-2013-0006.

Dobson,H., and C.B.Tomkinson.2012."Creating SustainableDevelopment ChangeAgents through 
Problem-Based Learning: Designing Appropriate Student PBL Projects.” International Journal of Sustainability in Higher Education 13 (3): 263-278. doi:10.1108/14676371211242571.

Galford, Gillian L., Ann Hoogenboom, Sam Carlson, Sarah Ford, Julie Nash, Elizabeth Palchak, Sarah Pears, Kristin Underwood, and Daniel V. Baker (eds.). 2014. Considering Vermont's Future in a Changing Climate: The First Vermont Climate Assessment. Burlington: Gund Institute for Ecological Economics.

Krajcik, J. S., P. C. Blumenfeld, R. W. Marx, and E. Soloway. 1994. "A Collaborative Model for Helping Middle Grade Science Teachers Learn Project-Based Instruction.” The Elementary School Journal 94 (5): 483-497.

Melillo, J. M., T. C. Richmond, and G. W. Yohe. 2014. Climate Change Impacts in the United States: The Third National Climate Assessment. Washington, D.C.: U.S. Global Change Research Program.

Wiek, Arnim, Angela Xiong, Katja Brundiers, and Sander van der Leeuw. 2014. "Integrating Problem- and Project-Based Learning into Sustainability Programs." International Journal of Sustainability in Higher Education 15 (4): 431-449. doi:10.1108/IJSHE-02-2013-0013. 